\title{
Notas sobre o Outro Lado das Fronteiras Míticas do Western
}

\section{Resumo:}

Tentaremos fazer uma breve panorâmica do delineamento do Oeste Americano (Ianque) enquanto designação de uma realidade geofísica, mas com fortes penetrações culturais e ideológicas na amplitude semântica do termo, atendendo a que, em última análise, o vocábulo circunscreve um espaço de confronto, beligerância e oposição entre o universo selvático e o da civilidade ou civilização, tendo em vista fundamentalmente abordar o processo da organização legal e jurídica da cidadania, representado nos westerns que tomam como temática central a instauração da lei e da ordem na sua dialéctica complexa com a dimensão da justiça. Nesta última oposição, redimensionam-se não só o confronto entre os colonos/ peregrinos europeus e os índios, como o dos modos de produção agrários, com estruturação de relações socioeconómicas esclavagistas ou quase feudais, com aquelas defendidas por uma mentalidade burguesa, capitalista e liberal e, ainda, a função destacada e o protagonismo dos representantes da lei, sheriffs e marshals.

Palavras-chave:

Fronteira, western, colonos/ peregrinos, índios, sheriffs, marshals

\section{Abstract:}

We will try to make a brief overview of the design of the American West (Yankee) as a designation of a geophysical reality but with strong cultural and ideological penetrations in the semantic amplitude of the term, being given that, ultimately, the word circumscribes a space of confrontation, belligerence and opposition between the savage universe, the wilderness and civility as civilisation, in order to fundamentally address the process of the legal and juridical organization of citizenship, represented in westerns that take as central theme the establishment of law and order in its complex dialectic with the dimension of justice. In the latter opposition, not only the confrontation between European settlers/pilgrims and Indians is resized, but also that of agrarian modes of production, with structuring of slave or almost feudal socio-economic relations, with those defended by a bourgeois, capitalist and liberal mentality and also the outstanding function and the protagonism of law representatives, sheriffs and marshals.

Keywords:

Frontier, western, settlers/pilgrims, indians, sheriffs, marshals 


\section{o - Espaços históricos e geográficos do Western}

Um imenso espaço físico político e social é referenciado dentro dos discursos que representam os seres, eventos e valores do universo criado segundo uma modelização artística a que se tem chamado western. O espaço/ real referido compreende, em linhas gerais, os territórios do Continente Americano que se encontram no Hemisfério Norte. Sobretudo os EUA, que podemos designar por Nação Ianque, mas, também, pontualmente, os Estados Unidos do México, e o Canadá, federação de territórios, governados, então, sob a égide do sistema monárquico parlamentar britânico, embora com bastantes autonomia enquanto domínio colonial, sobretudo durante todo o século XIX.

Paul Simpson, no seu The Rough Guide to the Western, 2006, afirma que a "verdadeira história do Oeste começou" quando os primeiros humanos atravessaram o estreito de Bering, da Sibéria para o Alasca, ${ }^{1}$ tendo sido 'descoberto' mais tarde por europeus que para lá se deslocaram como peregrinos ${ }^{2}$ colonos (pilgrims and settlers), ficando, num primeiro momento, o universo da colonização resumido a dois grandes grupos humanos: europeus e índios. É claro que, no western, a questão da mão-de-obra negra e da escravatura apenas surge, como tema, pela representação de episódios do confronto entre a União e a Confederação. Neste género, onde muita da história da América Ianque se revela, os índios são o outro, selvagem herege e vencido, e os negros são o outro, serviçal, submisso e esquecido e/ou apagado: imagem e espelho da humilhação (do outro) e da culpa (do Grande Outro, o senhor da linguagem e da lei plasmada por um poder sempre oculto ${ }^{3}$ ) que os vencedores assumem como trágica inevitabilidade.

Para alguns estudiosos do western, a realidade subjacente a essa matéria narrativa envolve muito mais do que a imagem dada pelas ficções e pelas narrativas, coevas, paralelas, quer de alguns relatos históricos, quer das lendas que se foram acumulando ao ponto de constituírem, estas, uma ampla e densa mitologia folclórica, a qual cimenta uma boa parte da cultura americana. Citando, mais uma vez, Simpson, podemos considerar que, para quem pretende compreender melhor o western, a história do Oeste ${ }^{4}$ terá começado em 1736, quando as autoridades coloniais britânicas, para evitarem tensões e confrontos com as tribos de índios, decretou que os colonos das suas colónias americanas deveriam instalar-se apenas a leste dos montes Apalaches (cf. Simpson 2006: 3), abrindo o precedente de uma fronteira civilizacional.

Ainda de acordo com a mesma fonte, podemos acrescentar que, uma vez obtida a independência (Declaração de Independência 1776, fim da guerra, com derrota dos ingleses, 1781), vinte anos depois, essa determinação legal foi banida, de tal modo que em 1807 os colonos começaram a instalar-se no Colorado, território que se situa quase no centro geográfico dos EUA, e, em 1840, alcançaram Oregon, nas costas do Pacífico. Raoul Walsh, no seu filme, The Big Trail (A Grande Jornada), 1930, dá-nos um relato épico, exemplar, dessa expansão, centrando-se na jornada de pioneiros, saídos de Saint Louis rumo ao Oregon, nas famosas caravanas (wagons), carroças cobertas, de tracção animal, bois ou cavalos, que se deslocavam, normalmente, em conjuntos enfileirados, em comboio (convoy). Neste processo, a fronteira reconfigura-se, tal como o passo de Requiem for a Nun, transcrito abaixo, exemplifica. 
O nascimento de uma capital de condado, durante o demarcar e nascer do estado de Mississippi, a partir de uma região anexada durante a guerra da independência contra a Inglaterra, segundo William Faulkner (excerto das primeiras páginas de Requiem For a Nun) pode ser um interessante documento de resumo, um exemplo da movimentação do "processo civilizacional", tal como o apresentamos aqui:

O TRIBUNAL pouco mais novo é do que a cidade que, à data da fundação, em meados do século, não passava dum entreposto comercial duma agência Chickasaw atirada para o cabo do mundo; durante cerca de trinta anos ninguém teve a ideia dum tribunal e não foi porque faltasse sítio onde instalar os arquivos ou porque um tribunal fosse assim tão indispensável para aquela gente, mas porque, enfim, só o criando ou pelo menos, só decretando a necessidade de criar um tribunal, se poderia fazer frente em qualquer altura a uma situação que, doutro modo, ainda poderia sair cara a alguém; / O pequeno grupo de colonos tinha os seus registos próprios; quanto mais não fosse, o simples acto de expropriação da terra dos índios, já se tinha tornado, com o andar dos tempos, num embrião de arquivos não falando já da papelada inerente à escalavrada confederação do homem contra o meio - tenha-se em conta a época e o estado selvagem do país - constituídos neste caso, por um magro punhado de documentos amarelecidos, esbeiçados, desconexos e, por vezes, redigidos de um modo quase incompreensível: actos de cedência e concessão de terras transferências, escrituras de venda, folhas de impostos e milícia, facturas de vendas de escravos, contas bancárias, de moeda falsa e de cotações ilegais de câmbio, ordens de arresto e hipotecas, listas de recompensas pela captura de negros e de outro gado fugido ou roubado, e ainda o registo, dia a dia, de nascimentos e matrimónios, de mortes e enforcamentos públicos, de leilões de terras - tudo isto a acumular-se lenta mente, durante três décadas, numa espécie de arca de pirata, chapeada de ferro, ao fundo da loja do edifício que servia ao mesmo tempo de estação de correio e de entreposto. Um nunca-acabar de papéis acumulados ali, até ao momento em que, trinta anos mais tarde, - depois de uma evasão com a qual anda associado certo velho e monstruoso cadeado de ferro - que fora transportado a cavalo de Carolina, numa distância de mil milhas - o baú foi colocado num pequeno compartimento de um telheiro ou casota de ferramentas, levantado dois dias antes contra a parede exterior da cadeia feita de toros, e calafetada a adôbe nas frestas, que a fuga dos presos abalara fortemente; e assim nasceu, sem que ninguém o pudesse prever, o tribunal do condado de Yoknapatawpha; um tribunal não só menos antigo do que a cadeia, mas nascido por mero acaso e acidente. ${ }^{5}$ 


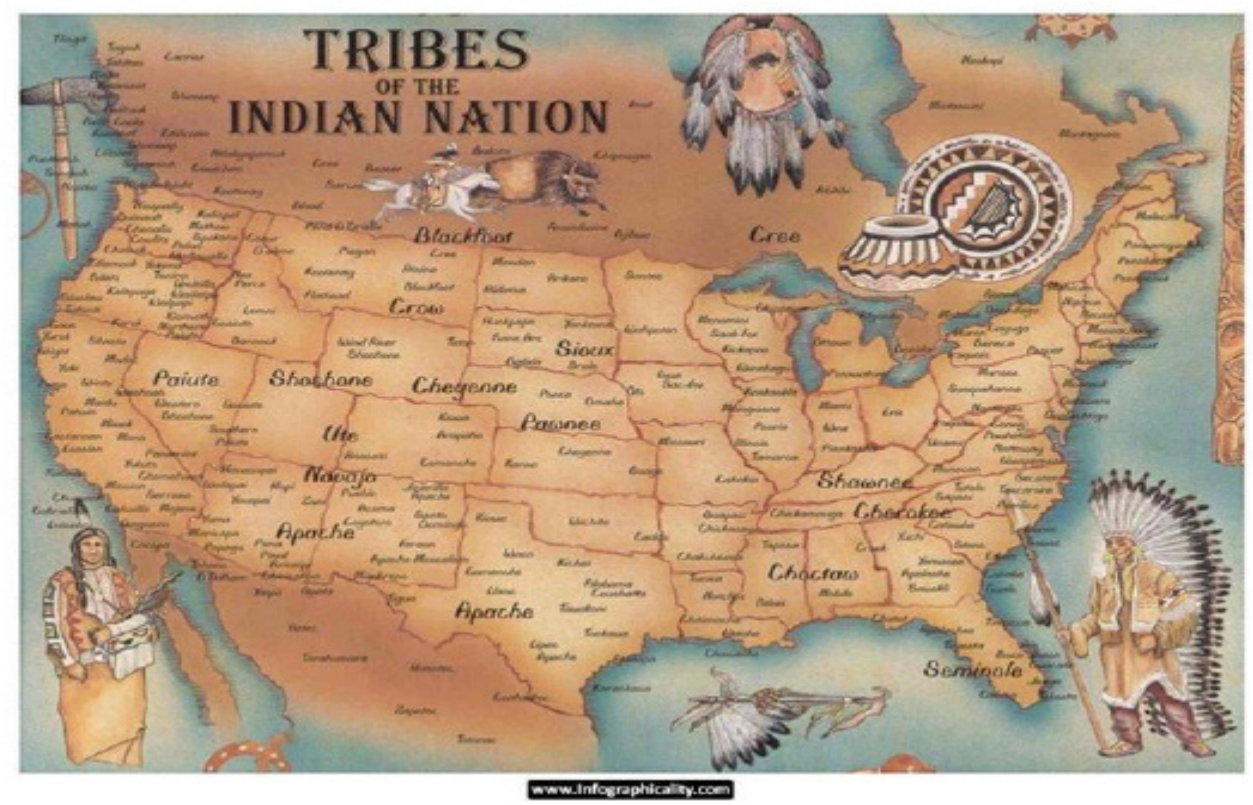

Num primeiro momento da sua consolidação, as nações índias que ficavam a leste do Mississippi foram recolocadas do lado Oeste do rio: em 1831, a tribo Choctaw, os Seminole em 1832, os Creeks em 1834, os Chickasaw 6 em 1837 e os Cherokee em 1838. A marca principal que registamos, na matéria legislativa respeitante aos índios, é a de que eles não faziam parte do Estado de Direito, e que as suas terras, ao serem incorporadas na nação, não integravam os seus habitantes nos direitos globais emitidos pelo governo central. Os seus direitos eram sempre exarados em acordos pontuais com cada tribo ou conjunto de tribos. Deixamos apenas, com estas breves notas e parcos apoios documentais, um pano de fundo géo-político, como parte da matéria introdutória inevitável, que não seria possível aprofundar aqui.

Tendo esse panorama geral presente percebemos melhor que a deslocação para Oeste, pelos anos 50 do mesmo século XIX, os colonos tenham conseguido criar um conjunto de estados significativo. A dicotomia que separa a civilização daquilo que os americanos, quase desde a origem, designaram por wilderness (ou sylvester: a região silvestre ou selvagem, poderíamos nós dizer em português, revelando a amplitude semântica do termo, pela conjunção alternativa). Neste avanço deu-se início à valorização da lei inscrita, quer a bíblica quer a laica, sendo esta, que trataremos neste nosso texto, profundamente imbuída daquela. E é o apelo aos fundamentos inscritos na Lei, que guia os intervenientes, nos litígios que constituem, quase sempre, a espinha dorsal dos westerns. 


\section{1 - 0 espaço aberto, a demarcação das terras e o confronto entre a lei e o poder das armas}

Pretendemos nesta reflexão sondar o as narrativas em que mais sistematicamente a questão da Lei, enquanto fenómeno sociopolítico, acompanhando a consolidação económica e a expansão da regulamentação das práticas sociais. Nestas narrativas, a Lei ou a palavra hortativa aparece mais como fenómeno jurídico e legal, do que como prática evangélica. $\mathrm{O}$ que não impede que a sua fundamentação, embora expressa num plano de discurso jurídico documentado historicamente, se deixe envolver por vezes em névoa encantatória que o discurso bíblico sustenta.

O emergir da memória épica dos primeiros pioneiros, das lendas da expansão com os seus peregrinos teve reformulações, em westerns de épocas recentes, revelando um cariz mais ou menos fantástico, mas sempre sugerindo o ocultou ou o indizível, ao conjugar-se na matéria mítica. O que acontece, de modo exemplar e fundador, num western como Shane, de 1952, de G. Stevens (cf. Jorge 2005). ${ }^{8}$ No fundo entre estes dois modelos de narrativas sobre a conquista do Oeste, o que pretende representar a instauração da lei como acto ou contrato político social, e o que vê no acto civilizador um avanço do verbo bíblico, verifica-se uma divisória que Patrick O'Donell, num texto sobre As I Lay Dying, coloca nestes termos: "entre a verticalidade da autoridade divina e a horizontalidade da autoridade civil [...]; entre o 'natural' e o 'cultural' " [...] (2010: 334).

Um ciclo que se centrasse na figura de Wyatt Earp, e nas dos seus familiares, irmãos, auxiliares e aliados, bem como dos seus adversários, permitiria ver como, das regras do mítico e da epopeia se passa às do romanesco, na sucessão de filmes que abordaram a sua figura. Apoiando-se em Lukács, ${ }^{9}$ Bernard Dort pode escrever que "a presença dos heróis do western já não têm a transparência através da qual resplandecia o sentido do mundo. Encontra-se obscurecido pelo medo e o temor existenciais" (1966: 68). Em grande parte, essa passagem produz-se no momento em que cessa a hegemonia da regra que sagra a natureza e em que o princípio naturalista, que alguns filósofos resumem no conceito de transcendentalismo americano, partilha o seu domínio, na dimensão ética, com o de progresso e de regulação da vida colectiva através da intervenção da lei laica, na regulamentação da vida social.

No que respeita às representações do universo social norte-americano, nas narrativas de beligerância e confronto a que, genericamente, chamamos westerns, sobretudo as referentes ao estado-nação que veio a ser os United States of America (desde que foi proclamada a sua independência do domínio inglês, em 4 de julho de 1776, por simplificação USA), na sua maioria situadas na segunda metade do século XIX e, só parcialmente, as referentes ao Canadá e ao México, na mesma época), devemos atentar num estado de coisas fundamental. Referimo-nos àquele em que, da ligação do homem à divindade, numa atitude que se manifesta, sobretudo, pelos modos como faz apelo e se rege pela lei divina, plasmada através da Bíblia, em práticas, hábitos costumes e breviários, se passou a uma fundamentação de valores que, sem proscrever ou abandonar os bíblicos, por vezes, até, apoiando-se amplamente neles, se articula e desenvolve num discurso laico, com base no texto constitucional e nas regras jurídicas mais amplas que a nação herda, sobretudo, dos códigos e das prática da jurisprudência inglesa e, através 
desta, do direito civil e criminal, na dimensão privada e pública, em funcionamento nos países europeus mais desenvolvidos na matéria - a França e a Alemanha, sobretudo.

O cristão que se desloca para a América é um peregrino que, em última instância vive a um ritmo em que a vida, quase despojada de técnicas e instrumentos sociais de alta elaboração, prevalece sobre a outra que, numa visão gnóstica, ${ }^{10}$ se exprime deste modo: "a humanidade é impulsionada para esse alargamento da consciência colectiva, em direcção à unidade, pelo progresso da técnica: [...] Ela aparece, poder-se-ia dizer, como um subproduto da actividade desenvolvida pelo homem quando persegue empiricamente essa finalidade mal definida: o Progresso" (Maravieff 1962: 105). Esta visão da questão é colocada, no século XIX, nos EUA pela filosofia transcendentalista. ${ }^{11}$

R. W. B. Lewis afirma sobre este tema no seu livro The American Adam que o mito americano encara "a história como se acabasse de ter início. Descreve o mundo a recomeçar, por uma nova iniciativa dada à espécie humana e garantida por Deus, uma vez que a primeira oportunidade foi tão desastrosamente explorada nas trevas crescentes do Velho Mundo" (cit. in Astre/ Hoareau 1997: 24). ${ }^{12}$

As comunidades de colonos e emigrantes que os westerns representam, numa situação de relativa estabilidade, não apaga completamente a dinâmica do nomadismo. Mesmo quando a intriga central não assenta, primordialmente, nas actividades a que podemos chamar nómadas, como as deslocações com rebanhos, dos vaqueiros, ou os avanços, em caravanas, para novas terras dos colonos agricultores, esse nomadismo faz-se sentir. Um contacto intenso entre o espaço de sedentarismo e o de mobilidade nómada permanece de um modo que se pode considerar relevante para todo o mecanismo da fabulação narrativa apresentada.

Segundo, ainda, Astre e Hoareau, "o western, de facto, terá explorado estas diversas orientações", que já acima sumariámos, e "alimentou-se, desde as suas origens até aos nossos dias, desses temas e das suas implicações" (1997: 25). Por isso mesmo, do ponto de vista desses autores, em muito coincidente com o nosso, "de facto, é em torno do debate entre a lei natural e a lei social que se organizam os filmes procedentes do Oeste...". Ou seja: "Neste universo, herdado do puritanismo dos predicadores, e dos Quakers, todas as coisas tendem a manifestar-se como incompatíveis", o que nos remete para uma espécie de visão do mundo basicamente esquizofrénica, com predominância paranoide, em que a posição e o interesse de cada pequeno grupo ou, por vezes, de cada indivíduo, é intolerável para o(os) Outro(s), e que, segundo os autores que vimos citando, "resulta (n)um sistema de antinomias e de antagonismos que dão" aos filmes desse género, ou às narrativas similares, literárias ou gráficas, um carácter simplista que, muitas vezes, "se lhes reprocha e que é propício a seduzir a moral ou mesmo a moral familiar" (Astre/ Hoareau 1997: 26). Em suma, as histórias contadas nesse tipo de obras, aproximam-se muito daquilo a que a retórica tem atribuído o nome de exempla, traduzindo, em latim os logoi ( $\lambda$ ó $\gamma o \iota)$, aristotélicos, ou seja, narrativas cuja estrutura simples da fábula ( $\mu$ v́$\theta$ os) se prestam a servir de exemplo, modelo de conduta, ou mesmo orientação ética ou ideológica. 
Porém, o Oeste, sendo uma "representação mítica", ou melhor, em nosso entender, mitológica, uma vez que não se revela apenas num imaginário de grande irradiação simbólica, mas em ciclos narrativos "do novo nascimento do homem, o lugar onde a organização da cidade se sucede à inocência, os dois elemento, O Bem e o Mal, devem enfrentar-se como o fizerem na história da fronteira" (Astre/ Hoareau 1997: 27), durante a qual se formaram os aldeamentos precários (settlements), dado que esta fronteira (frontier) definia, no primeiro momento da colonização, o lugar onde a "civilização" representada pelos colonos estacionados, quase sempre provisoriamente, se confrontava com a zona selvagem, a wilderness:

Com Cooper, ${ }^{13}$ enfim, a fronteira, dando entrada nas letras, tornou-se o grande mito americano, o factor mais importante da psicologia e da política americanas./ A frontier - a Pradaria - são as terras livres. São as terras livres do Oeste que recuam, segundo Tocqueville, trinta a cinco quilómetro por ano, ${ }^{14}$ mas que, até ao fim do século XIX, pareciam inesgotáveis, horizontes infinitos recomeçados eternamente, até um outro e problemático oceano, o Pacífico. A frontier, é muito mais do que o próprio símbolo dos recursos económicos inesgotáveis da América, muito mais do que a terra de quem se quer apropriar dela, e do fundamento teórico da nova democracia. A frontier, são as terras virgens, da inocência e do paraíso perdido, a imagem da civilização pastoril idílica, por oposição ao universo urbano. É a caução de pureza que lava os americanos dos seus pecados, do capitalismo, da industrialização das suas cidades desumanas. É a Terra prometida, onde a ausência de clausuras e a própria imensidão proclamam a bondade, a generosidade e a liberdade dos grandes homens brancos. É o términus da viagens de Bougainville, ${ }^{15}$ onde a utopia se realiza onde o homem branco se torna no «bom selvagem», sobre o qual se devaneava no século das Luzes. É a imagem que este país, nascido na idade da razão, faz de si mesmo, originado por um ideal de uma sociedade perfeita, de todas as utopias de que é feito o optimismo americano. (Cabau 1981:16-17)

A cidade sucede a esse horizonte da fronteira, instalando-se nele, com o mesmo sistema de referências, a que não falta um certo maniqueísmo puritano. Algumas dicotomias sobressaem nesse digladiar. Podemos acrescentar, aqui, às que já fizemos referência anteriormente, as formuladas pelos autores que vimos acompanhando: - a inocência e a experiência; ${ }^{16}$ o direito natural e o de cidadania; a aventura e a ordem; a religião natural e as igrejas; a economia instintiva e básica dos caçadores e agricultores, e a planificada e escrita das cidades e dos grandes empreendimentos agropecuários; o instinto (violento), e o autodomínio do homem educado ou experiente; ${ }^{17}$ o "herói" e o simples mortal; a inocência e a culpabilidade; o "pecado" e a "redenção"; o destino (fatal) e a liberdade; as forças da vida e as potências da morte (cf. Astre/ Hoareau 1997: 26-27). Por efeito dos campos semânticos de exclusão criados por esta dicotomia, dá-se, a um nível superior de entendimento, uma cosmização: uma delimitação ou delineamento inclusivo, que tem, por um lado, uma domesticação, por outro a indeterminação selvagem.

É interessante observar, apesar de tudo, o que nos diz Lévi-Strauss, sobre essa dicotomia, usando, porém, um feixe de conceitos mais elaborados: 
Cadernos de Literatura Comparada

Notas sobre o outro lado das fronteiras míticas do western

[...] começamos a compreender que a distinção entre estado de natureza e estado de sociedade, na falta de significado histórico aceitável, apresenta um valor lógico que justifica plenamente sua utilização pela sociologia moderna, como instrumento de método. [...]. É que a cultura não pode ser considerada nem simplesmente justaposta nem simplesmente superposta à vida. Em certo sentido substitui-se à vida, e em outro sentido utiliza-a e transforma-a para realizar uma síntese de nova ordem. Se é relativamente fácil estabelecer a distinção de princípio, a dificuldade começa quando se quer realizar a análise. (2009: 17-18)

O western, sobretudo quando pretende cingir-se a um rigoroso acto documental, pode considerar-se o tipo de narrativa em que as problemáticas apresentadas pelo antropólogo francês mais vivamente aparecem como auxiliares muito úteis. O histórico, que em todas as suas dimensões exige uma perspectivação ideologicamente cautelosa, evitando sobrepor os nosso desejos, limitações e crenças a uma delimitação eobservação dos factos, aparece aqui, sem excepções, marcado por algumas convicções elaboradas a partir dos mitos: um avanço civilizacional; uma sagração do mundo selvagem; uma moral de fonte bíblica; e um desejo de legitimação pela constituição e pela lei.

Assim, podemos ver nesse confronto uma permanente reactualização daquilo a que Mircea Eliade chama a cosmização:

O que caracteriza as sociedades tradicionais, é a oposição que elas subentendem entre o seu território habitado - e o espaço desconhecido e indeterminado que o cerca: o primeiro é o 'mundo' (mais precisamente, 'o nosso mundo'), o Cosmos; o restante já não é um Cosmos, mas uma espécie de 'outro mundo', um espaço estrangeiro, caótico, povoado de espectros, de demônios, 'estranhos' (equiparados, aliás, aos demónios e às almas dos mortos). À primeira vista, essa rotura no espaço parece devida à oposição entre um território habitado e organizado, portanto, 'cosmizado', e o espaço desconhecido que se estende para além de suas fronteiras: tem-se de uma parte um 'Cosmos' e de outra um 'Caos'. (Eliade 1978: 45)

Acrescente-se a estas, a dicotomia, bem mais importante e, sobretudo, imediata e específica, para traçarmos o objectivo da nossa análise. Trata-se daquela que nos lembra Hervé Mayer, entre decadência da civilização e regeneração, nos novos territórios : "Se o governo de Leste pode ser corrompido e tirânico, transportando a imagem canónica da velha Europa para os Estados Unidos, a Fronteira é o local onde essa civilização em declínio regenera as suas aspirações liberais e as suas instituições democráticas" (2017:161). Pois é a partir dela que, em grande parte, poderemos abordar, por exemplo, a filmografia referente a Wyatt Earp. ${ }^{18}$

Parece pertinente, aqui, uma outra observação que Eliade faz, um pouco adiante:

Se se trata de arrotear uma terra inculta ou de conquistar e ocupar um território já habitado por 'outros' seres humanos, a tomada de posse ritual deve, de qualquer modo, repetir a cosmogonia. Porque, da perspectiva das sociedades arcaicas, tudo o que não é 'o nosso mundo' não é ainda um 'mundo'. Não se faz 'nosso' um território senão 'criando-o' de novo, quer dizer: consagrando-o. 
Esse comportamento religioso em relação a terras desconhecidas prolongou se, mesmo no Ocidente, até a aurora dos tempos modernos. Os 'conquistadores' espanhóis e portugueses tomavam posse, em nome de Jesus Cristo, dos territórios que haviam descoberto e conquistado. A erecção da Cruz equivalia à consagração da região, portanto, de certo modo, a um 'novo nascimento'. (1978: 45-46)

Ocorre-nos, de imediato, que esse procedimento de conquista, por parte dos colonos, anglicanos, puritanos, e das várias extensões luteranas, revendo-se na exegese da Bíblia, não difere muito do dos conquistadores Ibéricos. Aspecto que se patenteia bem na importância das igrejas nos westerns em geral, as escolas, e mesmo o sistema de justiça e punição, da cadeia ao tribunal, como nos revela o texto de Faulkner acima transcrito. As cidades da fronteira, criaram-se e procuraram legitimar-se, segundo processos muito similares ao da cosmização tal como de todo e qualquer acto aculturador, pretendendo mesmo irradiar a auréola de civilização.

Ora, no seu todo, a cidade representada nos westerns, corresponde em grande parte a essa cosmização, em que o cosmos é oposto a um caos. Acontece mesmo que tudo em seu redor corresponde a um caos (dominado pelos índios mas, também por outro nómadas mais ou menos em contacto com a cosmização, como os cowboys, os fora-da-lei, ladrões e sanguinários, e os garimpeiros, por exemplo), pelo que se torna baluarte avançado, em paralelo, quase, com os espaços fortificados do exército.

Entendemos, assim, que a construção dessa figura divisória, no western, não escapa aos efeitos de mitologização. Como tentaremos demonstrar, através de algumas reflexões sobre matéria do faroeste,$^{19}$ afigura-se-nos que a questão mitológica nas narrativas da colonização dos Estados Unidos, tem dois níveis: um nível, a que chamaremos lendário ou mitológico, que mantém uma grande proximidade com a fonte original da matéria tratada. A concepção deste nível atende a que, como dizem Astre e Hoareau, " não existe nação moderna em que se mantenha tanto como nos EUA, uma relação 'dialéctica' entre o mito e a História" devido ao facto de "o acontecimento se ter sempre revelado, de 'se ter sempre divulgado', através do mito, o qual se cria, frequentemente, ao mesmo tempo que se desenrola a própria situação", através de "um labor de mitificação - ou fabulação" literário e folclórico, expresso em "contos populares, canções, imagens, novelas mais ou menos literáriase [e] espectáculos circenses" (1997: 26).

Estamos a tratar, aqui, do modo como o imaginário toma e entretece os elementos básicos, assentes em relatos tradicionais de testemunhas ou informadores, ainda que sem grande preocupação de evitar a perlaboração fabulatória. Trata-se de legendarização da matéria - a qual mantém, apesar de tudo, alguns fortes vínculos com a história -, da narrativização, mais ou menos fantasiosa, dos eventos e personagens históricas. É esta elaboração poética primária, modelização secundária, nos termos em que Lotman põe a questão, que dá origem ao nível que definimos em seguida.

O nível a que chamaremos mítico, que podemos considerar um outro nível, um para lá das exigências do factual, até pelo efeito complementar da criação, numa intensificação da fantasia, 
atingindo a dimensão que se aproxima do fabuloso ou mesmo do maravilhoso tem como elemento privilegiado o mitologema, reelaboração de uma matéria primária que está constituída por elementos mínimos ou mitemas, ${ }^{20}$ forjados no primeiro nível fabulatório, extraídos das factualidades vivenciais ou experienciadas, normalmente através de informador em segunda mão, do sujeito experienciador vital. Podemos dizer que é uma legendarização da matéria, em que passamos da fantasia para o fantástico, do enredo documentado, para o espectáculo encantatório: a mimese e a diegese elevam-se por total descolagem da factualidade histórica, ou para aquilo a que poderíamos chamar uma elevação no sentido do que se poderia chamar, uma modelização da própria modelização secundária: uma modelização em terceiro grau, para usarmos a recursividade hjelmslevina latente no conceito de Lotman. ${ }^{21}$

Para esta muito contribuiram, certamente, os "livros e panfletes" de que nos fala Mark Niemeyer, no seu trabalho sobre The Confidence-Man, de Herman Melville, livros que, na narrativa deste romancista, eram vendidos, a bordo do steamboat Fidèle, que navegava pelo Mississippi, transportando o tipos humanos mais comuns que frequentavam as suas margens, sendo uma boa parte viajantes que se deslocavam mais para Oeste, no fundo para a frontier, "uma zona de contacto na borda de uma linha de settlement" (fronteira mas no sentido ianque de expansão para Oeste, que contactava topograficamente com um assentamento de habitações, modelo de sedentarização de pioneiros recém-chegados) como diria o seu teórico, presiente dos EUA, em meados do século XIX, Frederick Jackson Turner. A primeira personagem que se destaca, na quase alegórica viagem que Melville narra, é um escroque ("chevalier" ${ }_{22}$ or swindler - Melville 1990: 7-11), "que vendia livros ou panfletos relatando a história de infames (infamous), de ladrões e criminosos violentos" (Niemeyer 2018: 127):

[...] incluindo a vida de Measan, o bandido de Ohio, Murrel, o pirata do Mississippi, e os irmãos Harpe, os Thugs ${ }^{23}$ da bacia de Green River, em Kentuky - criaturas, tal como outras equiparáveis, exterminadas uma a uma e, oportunamente, na sua maioria, como a perseguida geração de lobos da região, deixando poucos sucessores; o que parceria ser para causar a maior satisfação, e assim era para todos, excepto para aqueles que, nas novas regiões em que os lobos são abatidos, sofrem o aumenta das raposas. (Melville 1990: 8 [trad. CJFJ]) $)^{24}$

A estes, deveríamos, certamente, juntar os exempla, que foram uma quase cultura jornalística e de pulp fiction sobre a qual Faulkner tece, não só no texto acima transcrito, mas também através de uma das suas personagens de patético destino, em The Old Man, as seguintes considerações:

havia dois prisioneiros, um deles [tinha] um olhar indignado - um ultraje [...] dirigido aos escritores, aos nomes incorpóreos ligados aos contos, os romances de entregas - os Diamond Dick e os Jesse James e outros desse tipo -, que ele diz terem-no empurrado para sua condição actual por, na sua própria ignorância e credulidade [...] ter aceite a informação em que eles punham a marca da verosimilhança [...]. (1939: 435) 
Reportando-se esta história ao ano da grande cheia do Mississippi, 1927, ela plasma o testemunho de um atento agente cultural, ele próprio argumentista em Hollywood, onde trabalhou, sobretudo, com Howard Hawks, realizador profundamente empenhado no western e com quem colaborou, em 1934, no guião de Sutter's Gold, um western inspirado em L'or, de Blaise Cendras, de que o realizador acabou por desistir. ${ }^{25}$

Podemos dizer que o western é o género ficcional onde mais permanentemente se dá a tensão entre esses dois níveis emergentes da mitificação dos acontecimentos históricos, nomeadamente tomando as figuras típicas do fabulário milenar, como o que usam Melville e Faulkner: o mítico e o fantástico. Mas nenhum deles se torna procedimento exclusivo, sendo, apenas tendência dominante. Mesmo quando as temática abordadas se afastam dos temas mais antigos, que foram as épicas dos pioneiros, e a sua dimensão lendária, a estrutura das suas histórias pauta-se sempre por essa acção que é quase uma perlaboração, ou seja, um processo, mais ou menos inconsciente, pelo qual um realizador ou um escritor (ou, talvez, outro artista fabulador) integra uma interpretação e supera as resistências que ela apresenta face aos novos modelos sociais e às condicionantes, estéticas e éticas, de uma situação historicamente posterior.

Porque, evidentemente, não obstante termos considerado o western uma fabulação de forte componente mítica, em franca interpenetração com outras, sobretudo de cariz bíblica (os Testamentos bíblicos, as suas sequelas, como a Legenda Aurea, os romances de cavalaria, mas também muitos modelos da mitologia greco-romana e nórdica), o género não pode ser reduzido à ingenuidade de uma mitologia primitiva, como lembram Astre e Hoarau, sendo necessário "considerar o movimento da arte ao explorar segundo o seu modo próprio arquétipo e estereótipos, utilizando, além disso, as fábulas no sentido do conhecimento, em função das exigência próprias da história que se realiza" (1997: 16), nas diversas práticas, a diversos níveis, no quotidiano. Lembremos apenas como a imagem do índio, que, desde o "bom selvagem", mas ignorante e estúpido agressor (ainda patente nos westerns de Cecil B. De Mile), até ao "lúcido combatente" pelas causas da liberdade e do direito a escolher e praticar o seu modo de sustentação e sobrevivência, (como aparece em Bronco Apache, 1954, de Robert Aldrich), integrou-se como ícone em distintas mitologias e discursos ideológicos.

A análise de My Darling Clementine, 1946, que Fran Benavente pratica no seu El héroe trágico em el western, esclarece como os planos de filmagem têm um crescendo, simultaneamente de sentido e de graduação temporal narrativa: "Neste progressivo escalonamento dos planos estabelece-se uma modulação que mostra como a palavra trágica se acerca do seu verdadeiro detentor". E isso porque quando, no bar, os Clantons interrompem o actor que recita o célebre monólogo "ontológico" de Hamlet, é "o universo tenebroso da morte que se fixa sobre este herói cindido, trágico, afastado da épica áurea do westerner" ou seja, a personagem de Doc Holiday, aqui introduz a nota "do medo ao que está para lá da morte, o temor ante o vazio que atenaza o héroi trágico." e será a "a promessa [do] acesso a uma era de pleno sentido [...] cada vez que a confrontação adquire sentido articulada no mito progressista" (Benavente 2017: 96-97). É neste ponto que a lei começa a figurar no lugar dos princípios 
mais difusos da honra, da glória ou, mesmo, da expansão da fé pelo avanço dos colonos. E os heróis ou seus descendentes são os agentes da lei, por vezes com uma vivência mais prosaica e próxima do realismo romanesco.

A designação dos agentes de autoridade, que assumem funções de manter a ordem, obedecem a princípios legais plasmados em documentos com valor de lei (decretos - decrees - , por exemplo) emanados pelo poder central, federal, leis (ordinance) estaduais, emanados pelos governos dos estados e edictos (edicts) produzidos pelos poderes de vários níveis locais (que podem corresponder, aproximadamente, aos nossos éditos), como o do condado ou mesmo o da cidade. É importante notar que a designação do sheriff tende a ser local e depende, quase sempre, da votação (discutivelmente democrática) dos cidadãos ou habitantes do condado. $\mathrm{O}$ marshal, pode ser eleito por entidades ou assembleias qualificadas (poder autárquico e/ou judicial) da cidade, sendo essa designação usada, também, para os detentores do cargo de manter a lei a nível federal. Esta caracterização geral, ainda hoje se mantém.

Havia marshals da cidade. Estes existiam em cidades onde era necessária uma presença policial, mas a população da cidade era muito pequena para uma força policial completa. Muitas vezes essas cidades, no século XIX, eram comunidades realmente pequenas e às vezes nem sequer eram incorporadas (ou reconhecidas) pelo poder central, nem tinham entidade com poder legal institucional, ao passo que os marshals federais sempre foram agentes nomeados. A jurisdição dos marshal da cidade terminava nos limites da cidade, e estava subordinada, do ponto de vista legal, aos sheriffs, mas nem sempre prevalecia face ao poder das armas (caso que Warlock - O Homem das Pistolas de Ouro -, 1959, ilustra bem).

Sheriffs são, desde os tempos da fronteira, funcionários do condado eleitos pelos cidadãos do condado. ${ }^{26}$ Os sheriffs geralmente tinham jurisdição sobre todo o condado, incluindo todas as cidades naquele condado. No entanto, não havendo necessidade disso, geralmente deixavam esse a função para os marshals, ou nomeavam ajudantes (deputies).

Provavelmente o exemplo mais conhecido deste mecanismo de poder judiciário, e do processamento, por vezes complexo, das suas limitações nas situações de confronto e litígio, foi o da cidade de Tombstone, no condado de Cochise, Arizona, em 1881. Virgil Earp foi nomeado marshal da cidade, tendo os irmãos, Wyatt e Morgan, como assistentes. Nomeados desta forma, com apoio da Assembleia autárquica, não tinham jurisdição fora dos limites da cidade de Tombstone. Por outro lado, John Behan, era o sheriff (eleito) do Condado de Cochise e, sendo sensível aos interesses dos criadores de gado, não viu com bons olhos a portaria que interditava o porte de armas de fogo em público, decretada pelas autoridades municipais, a pedido dos Earps.

Tal proibição era uma tática dirigida, principalmente, contra o gang de roubo de gado, conhecida como cowboys. Mas visava, também, controlar o excesso de violência que se fazia sentir na cidade, gerado sobretudo pelo pessoal tendencialmente nómada que passava pela cidade, maioritariamente cowboys, mas não exclusivamente do gang que se autonomeava cowboys, suspeito de roubo de gado. Behan nunca interveio na tentativa de se opor, ou sobrepor a esta portaria, pelo que se podia subentender que a aceitava no seu espírito de tentar pacificar os ânimos. No entanto, a única vez que os Earps a impuseram, resultou no 
que é conhecido como "The Gunfight at the O. K. Corral". Sem qualquer tomada de posição prévia a favor ou contra da lei, depois do tiroteio acabar, Behan tentou prender os Earps e "Doc Holliday", levando-os a tribunal por assassinato, porque ele não reconheceu o direito do marshal a usar força mortal para impor as leis da cidade. No entanto, o tribunal acabou por justificar a actuação do marshal Earp, dos seus deputados e do seu amigo e activo apoiante, "Doc Holliday" que foi nomeado auxiliar, ou deputado, para a ocasião.

Além dos marshals nomeados pela instancia jurídica da cidade, assembleia autárquica ou representante judicial (juiz com cargo atribuído na cidade, ou sheriff do condado, p.e.) existiam os U.S. Marshals. Os federais foram (e ainda são) nomeados pelo Presidente para servir num distrito provido de tribunal federal, tendo em conta que cada estado ou território ${ }^{27}$ é dividido em distritos. Alguns estados têm apenas um, enquanto outros têm vários. Os U. S. Marshals, federais têm jurisdição legal em qualquer lugar dos EUA. Os seus poderes são quase coincidentes com os do sheriff, mas ao nível federal. Os federais e seus deputados raramente aplicavam leis estaduais ou locais, exceto em casos de corrupção ou onde as leis locais entravam em conflito com as leis federais.

Apresenta-se, no meio destas partilhas e distinções de poder, uma dimensão confusa. Muitas vezes os marshals da cidade também serviam, em tempo parcial, como sheriffs adjuntos. Isso ocorreu devido às distâncias entre as cidades e à quantidade de tempo necessária para regularizar situações conflituais por outra via. Porque esses vários oficiais só podiam impor leis na sua jurisdição que às vezes deixavam um vazio, por ausência de representante. Então, a deputação, por nomeação do poder central, de função e poder federal, a um representante de poderes locais e mesmo limitados (como era o caso dos town marshals) foi usada para preencher a lacuna.

Wyatt Earp, de Lawrence Kasdam, ilustra perfeitamente essa complexidade de interferências, interposições e cruzamentos de poderes, sobretudo entre o comunal ou da cidade, versus o do condado, personalizado pelo sheriff, com forte poder de base atribuido pelo acto eleitoral, podendo esse conflito ser agravado se, o marshal da cidade - escolhido e/ou contratado pelos select-man, pelas suas qualidades de combate - se bate pela defesa das normas que os representantes da cidade lhe propõem, principalmente quando o pedido é a obtenção da paz e da ordem nas ruas. Nesse caso exaram eles próprio as suas regras, embora com limitados poderes jurídico-administrativos e por tempo restrito, excepto se obtiverem apoio federal, através, sobretudo, do governo estadual que, por delegação do poder central, os pode nomear U.S. marshals. Foi essa nomeação de marshal federal que Wyatt Earp obteve para se sobrepor á pressão legal que o sheriff, enquanto autoridade do condado de Cochise, exercia sobre ele.

Tal conflitualidade latente, aparece muito bem retratada noutros westerns, como em Dead of a Gunfighter 1969, de Don Siegel, com Richard Widmark, em que a releção do marshal de cidade e o sheriff adquire o máximo relevo, quando este, usando a sua ascendência como representante do condado, tenta apaziguar os diferendos entre o agente da lei da cidade e os cidadão notáveis que que, embora o tivessem contratado, tentam excluí-lo, quando ele se torna incómodo para os interesses desses mesmo notáveis. 
Tudo isto era possível porque as cidades (ou township - comunas -, circunscrições de poder que podem não estar urbanamente agregadas como cidades, predominantes, sobretudo, no século XIX, na América, segundo refere Tocqueville), ${ }^{28}$ são a base do poder político nos EUA, que se instalou progressivamente nos territórios que se desenvolveram como partes do todo que compõe a União, num texto que data de 1835:

Na comuna, como em tudo o mais, o povo é a fonte dos poderes sociais, mas em nenhuma outra parte ele exerce seu poder de maneira mais imediata. [...] Não há conselho municipal; o corpo dos eleitores, depois de nomear seus magistrados, dirige-os ele mesmo em tudo o que não é a execução pura e simples das leis do Estado. [...] As funções públicas são extremamente numerosas e bastante divididas na comuna, como veremos adiante; no entanto, a maioria dos poderes administrativos está concentrada nas mãos de um pequeno número de indivíduos eleitos cada ano e que se chamam select-men (notáveis). [...] A lei do Estado os encarrega, por exemplo, de elaborar as listas eleitorais; se se omitirem [pessoas], tornam-se culpados de um delito. Mas, em todas as coisas que são deixadas à direção do poder comunal, os select-men são executantes das vontades populares, como entre nós o maire [prefeito - presidente da câmara, em Portugal] é o executor das deliberações do conselho municipal. (Tocqueville 1981: 124-127; sublinhados e negritos de nossa responsabilidade)

Isto ajuda-nos a perceber melhor o contexto que constitui o espaço físico e social, e o conjunto de valores que informa o sistema de referências e enquadramentos ideológicos que desenvolvem os westerns. Principalmente nos que mais directamente patenteiam o confronto entre os agentes da lei (em princípio executantes daquele conjunto de regras, regulamentações e formulações legislativas que se vai constituindo no discurso judicial laico, no qual, deve dizer-se, não deixam de ser sensíveis os reflexos do valores do texto bíblico) e os interesses imediatos das populações reais entre as quais eles vão actuar.

Se repararmos bem, os conceitos aqui apresentados sobre a lei laica e os seus agentes na sua generalização de princípios, situações e representações de estruturas institucionais, respeitantes aos diversos níveis sociais que são aludidos nos westerns - podem ser entendidas como referências de aceitável fidelidade à realidade histórica e geopolítica e mesmo geográfica, de todo o século XIX americano, mas sobretudo das décadas que se seguiram à Guerra da Secessão, propondo uma visão ficcionada, mas procurando esquivar-se às derivações fantasiosas, muitas vezes usando técnicas de distanciamento e relativização que se aproximam muito dos enredos romanescos. O ícone de uma tal elaboração literária bem podia ser, pela sua posição poética, referencial e inspirador, o romance The Virginian: A Horseman of the Plains, 1902, de Owen Wister. 


\section{NOTAS}

* Carlos Jorge Figueiredo Jorge é Professor Emérito, Jubilado, Associado, com Agregação, da Universidade de Évora, onde ensinou Literatura Comparada e Teoria da Literatura. Últimos Livros publicados: 2018 - Moradas, aparições e Intrigas; 2014 - Interdição e Restrição no Amor - Enredos Amorosos do Século XIX, Apenas Livros, Lisboa. 2012 - Plágio - Propriedade e Apropriação em Eça, Zola e Outros..., Apenas Livros, Lisboa; 2011 - Histórias, Imagens e Letras - Literatura e Cinema numa Perspectiva Comparatista, Apenas Livros, Lisboa. Artigos recentes: 2020 - "As Deslocações da Visão Ou A Coscuvilhice do Olhar Alucinado. Quando o Observador se Move à Distância" in Cherchez les femmes, ILC/Afrontamento, Porto; 2020 - "A Influência do Cinema no Neo-Realismo Português" in Nova Síntese, APMN-R/Colibri, Vila Franca de Xira.

${ }^{1}$ Esta teoria foi proposta inicialmente no ano de 1590 d.C. por José de Acosta (jesuíta espanhol que foi para o Peru no séc. XVI) mas só passou a ser credível a partir da década de 30 do século passado. Actualmente, é consenso entre os especialistas que, durante a última era glaciar, a concentração de gelo nos continentes fez descer o nível dos oceanos em pelo menos 120 metros. Esta descida provocou, em vários pontos do planeta, o aparecimento de diversas conexões terrestres.

Cf. <https://pt.wikipedia.org/wiki/Povoamento_da_Am\%C3\%A9rica>

${ }^{2}$ Mayflower (em português, literalmente "flor de Maio") foi o famoso navio que, em 1620, transportou os chamados Puritanos Ingleses, designados, posteriormente, "Peregrinos" ("Pilgrims"), do porto de Southampton, Inglaterra, para o Novo Mundo. Cf. <https://pt.wikipedia.org/wiki/Mayflower>

3 “[...] O Outro absoluto, é aquele em que nós nos endereçamos para além desse semelhante, aquele que nós somos forçados a admitir para além da relação espelhar, aquele que aceita ou que se recusa em face de nós, aquele que tem a oportunidade de nos enganar, em que não podemos jamais saber se ele não nos engana, aquele em que nós nos endereçamos sempre" (Lacan 1981: 286-287). Assim o Outro é fundamentalmente aquilo a partir do qual o discurso se constitui como Lei, neste caso, como complementar ou substituto de um poder fantasmático ou mítico que viria de uma instância quase mágica a que, na expansão do ocidente, se chamou RAÇA ou ESTIRPE - configurações regulamentadas quase a partir do inconsciente, sob fortes pulsões do id ou conformadas pelo superego.

4 West, por vezes evocado como Far-West, e muitas vezes dito, em português, "Faroeste", quando falamos em filmes de "Caubóis", e não em westerns, ou filmes de cowboys.

${ }^{5}$ Apresentamos, aqui, a continuação da descrição fundamental do nascer da lei e das suas sedes, numa cidade americana, segundo Faulkner, em Requiem for a Nun, procurando assim completar a informação sem sobrecarregar o texto principal: "O caixão, que continha os documentos, não mudara de lugar; levaram-no simplesmente para qualquer parte. Não foi por qualquer razão inerente ao baú ou à loja das traseiras que o tiraram donde ele se encontrava, antes pelo contrário, pois não constituía empecilho para ninguém naquele compartimento, e a sua falta sentiu-se imediatamente. Com efeito, nas noite de invernia servira de assento ou de banca junto do fogão, entre barris de pólvora e whisky, barricas de sal e banha; e foi transferido pelo único motivo de que, subitamente, a povoação (no espaço duma noite esta pequena colónia iria tornar-se numa cidade, sem nunca na vida ter sido sequer aldeia; e quase um século depois iria despertar freneticamente da sua modorra comunal para se desentranhar em Rotários e Lions Clubs, câmaras de comércio e sociedades de urbanismo: um rufar furioso de tambores ocos sem outro destino que não fosse o de fazer mais ruído do que o pequeno aglomerado humano mais próximo, tanto a norte, como a sul, a leste como a oeste, proclamando-se 'cidade', da mesma maneira que Napoleão se proclamou imperador, e defendendo tal expediente enchumaçando um pouco as listas de recenseamento - uma febre, um delírio, que a levaria a confundir para sempre o frenesim com o movimento e o movimento com o progresso. Mas isto fora há uns bons cem anos, agora era a vida de fronteira; homens e mulheres eram pioneiros, rijos, simples e coriáceos, em busca 


\section{Cadernos de Literatura Comparada}

Notas sobre o outro lado das fronteiras míticas do western

de dinheiro ou aventura, de liberdade, ou de evasão, sem cuidarem demasiado do modo como o faziam) a povoação viu-se colocada não tanto perante um problema que deveriam resolver, mas em face de um dilema, verdadeira espada de Damocles, de que tinha de desenvencilhar-se, desse por onde desse;

Até a própria evasão dos pioneiros fora afinal obra do acaso: Um grupo de bandidos - três ou quatro da cidade de Natchez (vinte anos mais tarde a lenda havia de afirmar, e cem anos depois ainda o repetiria, que dois dos bandidos eram os Harpes em pessoa, pelo menos o Big Harpe, visto que as circunstâncias, o método da evasão, tinham deixado como que um rastro, qualquer coisa como um odor, uma espécie de boa farsa pantagruélica e bizarra, ao mesmo tempo cómica e aterradora, como se a pequena colónia tivesse caído, por engano, debaixo dos olhos ou nas proximidades de algum gigante ocioso e fantasista. Ora essa ideia - a ideia de que tivessem sido os Harpes - era impossível de aceitar, visto que os Harpes, e o último dos malandrins da família Mason, já tinham morrido a esse tempo ou andavam dispersos; donde, os ladrões terem que pertencer à organização de John Murrel admitindo que fosse forçoso que pertencessem a qualquer outra coisa que não a uma simples confraria da rapina), três ou quatro bandoleiros foram capturados ao acaso por um bando improvisado de civis, mais ou menos milicianos, que os levou para a Cadeia de Jefferson por ser a mais próxima. Tal bando era apenas uma parte de uma vasta concentração que se fizera em Jefferson, dois dias antes, por altura do arraial do Quatro de Julho, arraial que, ao fim do segundo dia, se reduzira, por uma rija eliminatória, às proporções de uma rixa de bêbedos que deixou até os mais duros dos sobreviventes vulneráveis à expulsão da colónia por parte da população civil. Os membros desse bando que, mais tarde, iria fazer a caça aos bandidos de Natchez Trace foram transportados mortos de bêbedos, numa carroça que os baldeou, a quatro milhas de Jefferson, num pântano conhecido pelo nome de Hurricane Bottoms. Ali acamparam para recuperarem forças, quanto mais não fosse a força das pernas, e foi então que os três ou quatro bandoleiros que seguiam a caminho do seu esconderijo, após a última proeza praticada, foram esbarrar com a fogueira do acampamento. Neste ponto, os relatos divergem: dizem uns que o sargento que comandava a milícia reconheceu num dos bandidos um desertor da sua unidade, contam outros que um dos bandidos reconheceu no sargento um seu antigo camarada de ofício. Fosse como fosse, o certo é que na madrugada do quarto dia todos eles, captores e prisioneiros, regressaram em grupo a Jefferson. Há quem garanta que esta bela aliança à última hora foi motivada por um desejo comum de voltarem às tabernas, mas há quem afirme que não, que os milicianos trouxeram os presos para a aldeia precisamente para darem uma bofetada de luva branca à população civil que os tinha expulso dali. Porque estes eram os tempos em que a vida da fronteira estava no auge, tempo de pioneiros, tempo em que a liberdade individual e a liberdade colectiva eram quase uma condição física, como o fogo e a inundação, e jamais um povoado se imiscuiria em princípios de moral, desde que o amoralista fosse exercer os seus talentos em qualquer outro lado. Ora como Jefferson não ficava nem na Pista de Natchez, nem no Rio, mas a meio caminho, naturalmente que dispensava a escumalha destas duas regiões;

Mas agora os colonos viam-se a braços com gente desta, tomados de surpresa, desprevenidos, sem aviso que lhes permitisse prepararem-se e protegerem-se. Meteram os bandidos na cadeia de toros com as fendas calafetadas a adobe, cadeia que, até então, nunca conhecera ferrolho visto que os seus clientes tinham sido amadores sem perigo: brigões do sítio, ébrios e escravos foragidos - gente que se guardava com um barrote de pau bem pesado corrido entre dois grampos pelo lado de fora da porta, como numa granja. O pior era que a coisa agora tinha mudado de figura; tratava-se de três ou quatro indivíduos, que podiam muito bem ser os Dillingers ou os Jesse James do seu tempo, e com cabeça a prémio. De modo que puseram um fecho na cadeia. Furaram a porta com uma broca; fizeram outro buraco na ombreira, passaram através dos dois buracos uma grossa corrente, e enviaram um mensageiro aos correios para que procurasse o velho cadeado de Carolina, que devia ter chegado com o último saco do correio de Nashville. Era um verdadeiro monstro de ferro, com perto de quinze libras de peso e uma chave do tamanho duma baioneta, e que era não só o único como o mais antigo cadeado daquele recanto dos Estados 
Unidos. Tinha sido trazido para ali por um dos três homens que iriam ser os pioneiros e colonos do condado de Yoknapatawpha, e cujos nomes figurariam entre os dos mais antigos da região - Alexandre Holston, que para ali fora com o doutor Samuel Habersham na qualidade de eguariço e guarda-costas, servindo igualmente de enfermeiro e perceptor do filho-sem-mãe do médico, uma criança de oito anos. Chegaram os três a cavalo, vindos de Cumberland Gap, através do Tennessee, na companhia de Luís Grenier, o jovem huguenote, que introduzira os primeiros escravos no país e recebera o primeiro título duma grande propriedade, tornando-se assim o primeiro roceiro de algodão. Entretanto o Dr. Habersham, com a sua maleta usada, cheia de pílulas e de escalpelos, o seu guardaᄀcostas musculoso e taciturno e o seu menino meio órfão, tornou-se a própria colónia (durante algum tempo, antes de lhe darem um nome, dizia-se Casal do Doutor Habersham, depois Aldeia de Habersham, depois simplesmente Habersham). Cem anos mais tarde, durante um cisma de dois clubes femininos sobre a denominação das ruas, a fim de beneficiar da gratuitidade do serviço postal, foi feita uma campanha destinada primeiramente a restaurar o nome de Habersham. Em seguida, como tivesse falhado o movimento, pretendeu-se dividir a cidade em duas, dando a uma parte o nome de Habersham, em memória do velho doutor que a fundara). Holston era amigo de Issetibbeha, o velho chefe Chickasaw (o filho de Habersham, a criança-sem-mãe, que tinha agora vinte anos, casara com uma das netas de Issetibbeha e, nos anos de 1830 a 1840, emigrara para Oklahoma com a família da mulher, que tinha sido desapossada de todos os bens) Holston, a princípio agente oficioso, depois encarregado da firma Chickasaw, até ao dia em que se demitiu numa carta de denúncia furiosa dirigida com todas as letras ao próprio Presidente dos Estados Unidos. E quando a criança que tinha sob tutela e a quem ensinava, atingiu a maioridade, Alexandre Holston tornou-se o primeiro publicano da colónia, abrindo uma taberna que ainda hoje é conhecida pelo nome de Holston House. As paredes eram de madeira, o sobrado assente em estacaria, as juntas entalhadas à mão. Tudo isto deve estar hoje oculto em qualquer parte sob uma massa de vidros, de tijolos envernizados e de tubos de néon. Era a ele que pertencia o cadeado"; (Faulkner 1958: 21-26)

${ }^{6}$ A presença e remoção dos Chickasaw das suas terras nomeadamente a norte do estado do Mississípi, é amplamente descrita por Faulkner em várias das suas narrativas mas, sobretudo, nos longos escursos-didascálicos da sua peça, Requiem for a Nun (1951), que o excerto acima apresentado ilustra.

7 "O conceito de wilderness aciona valores e significados de caráter universal que se traduzem, no contexto da sociedade secularizada, numa idealização da natureza como fonte atemporal de uma ética laica e de uma ascese ecológica. Esse conceito, por sua vez, em alguma medida, reitera, na imaginação dos sujeitos que se pensam modernos e civilizados, o mito do bom selvagem, que está na base da narrativa da colonização da América. O embate agonístico entre o primitivo e o civilizado estende-se, assim, para o campo ambiental, numa nova versão romântica da luta épica entre a maligna civilização e a benigna natureza. Assim, a negação da natureza na empresa civilizacional - como o outro da cultura - age como um recurso imaginativo que possibilita uma experiência de transcendência no âmbito da sociedade secularizada. A alteridade fundante do humano que se expressava, na narrativa cristã, pela oposição radical entre criador e criatura, desloca-se para a oposição entre cultura e natureza. Um marco fundamental na produção do conceito de wilderness é a obra e a vida exemplar de Henry David Thoreau (1817 - 1862), autor de Walden ou a vida nos bosques. Nesse livro, Thoreau propõe a criação de um mundo alternativo à sociedade moderna da época, baseado na desobediência civil e na autossuficiência, expressas na recusa ao mercado e numa ascese pautada pela autolimitação no uso de bens de consumo. Prega, assim, o ideal de uma vida simples junto à natureza". (Carvalho/Steil 2013: 1)

${ }^{8} \mathrm{O}$ último parágrafo do livro resume essa dimensão, pela "voz" do narrador, recordando a infância durante a qual Shane se revelou, pelo que damos, dele, a nossa tradução: "Ele era o homem que chegou, a cavalo, ao nosso pequeno vale, vindo do coração cintilante do Oeste e, depois de realizar a sua missão, cavalgou para o lugar de onde viera, e ele era Shane" (Schaefer 1975: 151) 


\section{Cadernos de Literatura Comparada}

Notas sobre o outro lado das fronteiras míticas do western

9 "O romance é a epopeia de um tempo em que a totalidade extensiva da vida não é já dada de maneira imediata, de um tempo para o qual a imanência do sentido à vida se tornou problema, mas que, apesar de tudo, não cessou de aspirar à totalidade" (Lukacs 1986: 61).

${ }^{10}$ Designamos por este termo o conjunto das manifestações cristãs que, sobretudo na América, se desenvolveram de modo muito alargado, procurando os poderes que se iam instituindo fixar uma ortodoxia cristã transcendente às diversas igrejas bíblicas que manifestavam livremente, e quase sem confrontos, os seus credos, valores e profecias. É preciso reconhecer que a religiosidade relectida pelo western é eminentemente profética e hortativa, profundamente arreigada às práticas quotidianas das sociedades que representa.

11 "O maior deleite que os campos e os bosques comunicam é a sugestão de uma oculta relação entre o homem e os vegetais. Não estou só, nem ignorado. Fazem-me sinais e eu lhes respondo. O balanço das ramas em meio a tormenta é para mim novo e antigo. Toma-me de surpresa e, apesar disso, não me é desconhecido. Seu efeito é semelhante ao do alto pensamento ou à emoção sublime que me invade quando julgo que estou raciocinando com acerto ou que estou trabalhando corretamente. Mas o poder de produzir esse encanto não reside na natureza, sem dúvida, senão no homem ou na harmonia de ambos. É preciso fazer uso desses prazeres com grande moderação; pois a natureza nem sempre se disfarça com roupa de festa, e a mesma cena que ontem perfumava e reluzia como para que dançassem as ninfas, hoje está coberta de melancolia. A natureza tem sempre as cores do espírito. Para um homem acometido pela calamidade, o calor de sua própria lareira seria em si mesmo triste. Há também uma espécie de desprezo pela paisagem, o que sente aquele que acaba de perder um amigo querido, e então o céu já não é tão vasto e nem tão valiosa é a população sobre a qual se extende" (Emerson 2011: 11)

${ }^{12}$ The American Adam, Prólogo, pág 5. <https://archive.org/details/americanadam030355mbp/page/n17/mode/2up>

${ }^{13}$ James Fenimore Cooper, é um dos autores que fundaram a literatura americana e, sobretudo, pelo conjunto de romances que têm, como figuras mais destacadas, os colonos e índios caçadores e que foram designados como um todo sob o título Leatherstocking Tales. A principal personagem da série, que, por assim dizer, a unifica, é Natty Bumppo, caçador branco que se celebrizou, sobretudo no romance The Last of the Mohicans: A Narrative of 1757, de 1826, nomeadamente pelas suas adaptações ao cinema e às graphic novels.

${ }^{14}$ La Democratie en Amerique, I vol. $2^{\mathrm{a}}$ parte, cap. 10, § 4, (1981: 498) “Das margens do lago Superior ao golfo do México, há, em linha reta, cerca de quatrocentas léguas francesas. Ao longo dessa imensa linha serpenteia a fronteira dos Estados Unidos; às vezes ela entra por esses limites adentro, quase sempre penetra muito além deles, em meio aos desertos. Calculou-se que, em todo esse vasto frontal, os brancos avançavam cada ano, em média, sete léguas". Trad. de Eduardo Brandão; ver o original e, também, em torno da mesma temática, na mesma obra de Tocqueville, (1981) pp. 383 a 390, 449 e 489.

${ }^{15}$ Voyage autour du monde, 1771, é um livro escrito pelo explorador francês Louis Antoine de Bougainville, que tornou o Taiti famoso na Europa. Descreve a ilha como um paraíso na terra, onde homens e mulheres viviam felizes em inocência, distantes da corrupção da civilização.

${ }^{16}$ Que tem um exemplar quase perfeito no fime de Antony Man, The Tin Star, 1957.

${ }^{17}$ Conjunto que subjaz a toda a saga de Wyatt Earp, nas variadas narrativas que sobre ele se construíram, no cinema e em narrativas verbais ou gráficas que foram adaptadas para o cinema.

${ }^{18}$ Wyatt nasceu em Illinois, em 1848. Em 1864 mudou-se com seus pais para Califórnia. Regressou a Leste e onde se casou e enviuvou. Trabahou como caçador do búfalo e guia de diligências. Em 1875, foi marshal em Wichita. Em 1876, mudou-se para a Dodge Citty, Kansas onde encontrou com Bat Masterson e Doc Holliday, e estabeleceu a sua reputação como sheriff e jogador notável. Em 1879 juntou-se aos seus irmãos e esposas na cidade mineira de prata, Tombstone, no Arizona. Seu irmão Virgil tornou-se marshall da cidade, e nomeou o outro irmão, Morgan, seu auxiliar. Em 26 de Outubro de 1881, uma disputa 
entre os irmãos Earp e um grupo conduzidos por Ike Clanton culminou no tiroteio mais comemorado do folclore norte-americano - o Tiroteio no OK Curral. Três do grupo de Clanton morreram, Ike e um outro membro ferido conseguiram escapar. Três irmãos Earp - Virgil, Wyatt e Morgan - junto com o "Doc Holliday" sobreviveram. Morgan e Virgil foram feridos, e Virgil deixou de ser marshall por sua participação nos homicídios. Em março de 1882 Morgan Earp foi assassinado por desconhecidos. Wyatt, junto com seu irmão Warren e alguns amigos, perseguiram os suspeitos do assassinato durante algumas poucas semanas e a "vendetta" resultou em mais quatro mortos. No final da vida, com o sucesso dos filmes de Hollywood sobre o Velho Oeste, Earp chegou a relacionar-se com alguns actores célebres do género, como Tom Mix e John Wayne. John Ford realizou o seu filme sobre o tiroteio do "OK Corralos" em 1946, My Darling Clementine (pt.: A Paixão dos Fortes), tendo Henry Fonda como Wyatt Earp, e alardeava que teria ouvido a história da própria personagem real. Anos depois, teria admitido que nem tudo era a verdade, ao dizer algo como "Se a lenda for melhor que a realidade, filme-se a lenda", tema de um de seus últimos grandes westerns, The Man Who Shot Liberty Valance (pt.: O Homem que Matou Liberty Valance), de 1962. Para mais informações sumárias ver, por exemplo <https://pt.wikipedia.org/wiki/Wyatt_Earp>.

Outros, como Strurges, Tourneur, Kasdam, e Cosmatos voltaram amplamente às mesmas personagens, por vezes com elencos mais alargados (sobretudo Kasdam). Mas aparecem registos desse filão da matéria, e variantes, em muitos realizadores, sendo Forty Guns (Quarenta Cavaleiros), 1957, de Fuller o mais carismático entre os cinéfilos.

${ }^{19}$ Entendemos, aqui, o conceito de matéria equivalente ao que usamos quando nos referimos às narrativas europeias mais antigas: Matéria da Bretanha (segundo o poeta francês do século XII, Jean Bodel) é um nome dado às lendas, em geral de origem celta, relacionadas com a história da Bretanha e das Ilhas Britânicas. As histórias mais conhecidas são que se centram na figura do rei Artur e seus Cavaleiros da Távola Redonda. O espírito que rege estes, está muito próximo do de alguns heróis, cavaleiros, que se batem, no Oeste Americano, pelos fracos, injusticiados ou oprimidos.

A designação, "matéria" identifica os temas (no sentido em que Genette fala de histoire*) das narrativas relativas às origens míticas da Bretanha (para uma mais completa elucidação destes assuntos, ver de Carlos García Gual, Los origines de la novela, 1988, Istmo, Madrid e Primeras novelas europeas, 1990, Istmo Madrid). Ver também, <https://pt.wikipedia.org/wiki/ Mat\%C3\%A9ria_da_Bretanha> onde aparece sumariada alguma informação.

*Em Discours du récit (Figures III. Paris: Éditions du Seuil, col. "Poétique", 1972, p. 71-73), Gérard Genette, baseou a sua narratologia na distinção entre história (a sucessão de eventos relatados pela narrativa), a narrativa /récit, em francês ("a declaração narrativa, o discurso oral ou escrito que assume a relação de um evento ou uma série de eventos") e a narração ("o acto de narrar em si mesmo" e, por extensão, a situação em que ocorre). E o objeto principal dessa narratologia é a narrativa, o nível que por si só "se oferece diretamente à análise textual", aquele a partir do qual os outros dois podem ser vistos.

${ }^{20}$ Segundo Gilbert Durand, "os mitemas são pontos fortes, repetitivos da narrativa./ O mitema é amais pequena unidade significante" (1983: 29) e: "Um mitologema é um resumo, de certo modo, de uma situação mitológica, um resultado abstracto. É uma simples esqueleto da obra" (1983: 32).

${ }_{21}$ "Por 'sistema modelizante secundário' entendemos um sistema significante com apoio no qual construímos modelos de do mundo ou fragmentos dos mesmos" (Ivanov et alii 1970: 149)

${ }^{22}$ Espertalhão, escroque, indivíduo que vive de expedientes. No fundo um oportunista que aparenta o empreendedorismo, segundo a expressão francesa "chevalier d'industrie".

${ }^{23}$ Bando de assassinos particularmente ativos, no norte da Índia, durante o século XIX, contra a ocupação inglesa, que adoravam Kali, à qual ofereceram as suas vítimas, estranguladas ritualmente. A actuação militar-colonial inglesa parece ter conseguido extinguir a seita.

${ }^{24}$ Eis o parágrado original de onde traduzimos o excerto apresentado acima: "As if it had been a theatre-bill, crowds were 


\section{Cadernos de Literatura Comparada}

Notas sobre o outro lado das fronteiras míticas do western

gathered about the announcement, and among them certain chevaliers, whose eyes, it was plain, were on the capitals, or, at least, earnestly seeking sight of them from behind intervening coats; but as for their fingers, they were enveloped in some myth; though, during a chance interval, one of these chevaliers somewhat showed his hand in purchasing from another chevalier, ex-officio a peddler of money-belts, one of his popular safe-guards, while another peddler, who was still another versatile chevalier, hawked, in the thick of the throng, the lives of Measan, the bandit of Ohio, Murrel, the pirate of the Mississippi, and the brothers Harpe, the Thugs of the Green River country, in Kentucky - creatures, with others of the sort, one and all exterminated at the time, and for the most part, like the hunted generations of wolves in the same regions, leaving comparatively few successors; which would seem cause for unalloyed gratulation, and is such to all except those who think that in new countries, where the wolves are killed off, the foxes increase." (Melville 1990: 7-8)

${ }^{25}$ Para não nos alongarmos, deixamos aqui apenas três referências sobre a questão das variadas colaborações de Faulkner na escrita de argumentos, para lá daquelas estabelecidas pela adaptação de livros seus: mesmo sem ser creditado, teria colaborado no roteiro de Drums Along de Mohawk, 1939, de John Ford, além da participação que originou esta nota - cf. Fábio Luis Rockenbach, https://revistamoviement.net/ao-rufar-os-tambores-john-ford-c080686be11d -, o que eleva para duas as suas participações em filmes relativos ao nascimento dos EUA e à saga de civilização e avanços para Oeste; o tema da cadeia, no western, o seu funcionamento como significante simbolicamente polissémico e sugestivo em Hawks, em três filmes (Rio Bravo, 1959, El Dorado, 1966, e Rio Lobo, 1970) bem se pode dever à influência que sobre ele terá exercido Faulkner, do qual deixamos aqui expresso o escurso didascálico sobre a cadeia na sua peça, Requiem For a Nun, 1951; curiosamente, com argumento de Claudio Nizzi e desenhos e capa Magnus apareceu, em1996, uma banda desenhada tendo como herói o ranger TEX, figura criada pelo italiano Gianluigi Bonelli, fundador da editora que o publica em Itália. A matéria é aquela em que Hawks e Faulkner trabalharam, ainda que com uma tecedura efabulatória mais apropriada à BD, como informa a sinopse publicitária: "Crimes hediondos estão dizimando os habitantes de um vale fértil na bacia do Rio Sacramento, onde reside John Sutter, outrora conhecido como o Imperador da Califórnia, homem empreendedor que logrou grande desenvolvimento sócio-econômico para a região, e que foi subitamente engolido pela Corrida do Ouro, que trouxe milhares de garimpeiros para a região e o deixaram na mais absoluta miséria." A personagem, que foi real, teve a sua notabilização literária na narrativa de Blaise Cendrars, L'or, 1925.

${ }^{26}$ Como lembra Tocqueville: "A comuna tinha uma extensão demasiado restrita para que se pudesse encerrar nela a administração da justiça. O condado constitui, pois, o primeiro centro judiciário. Cada condado tem um tribunal de justiça, um sheriff para executar as decisões dos tribunais, uma prisão que deve conter os criminosos." (1981: 133- O sublinhado e o negrito são nossos, CJFJ).

${ }^{27}$ Zona já administrativamente delineada, mas que ainda não obteve todos os requisitos para ser nomeada estado. Um bom exemplo do funcionamento dos mecanismos de delegação de poderes num território, aparece em Hang them High (A Sombra da Forca), 1968, de Ted Post, onde os agentes do gabinete de U.S. marshals, se moviam e actuavam sob a ordem directa de um juiz territorial (territorial judge) sob auspícios do poder central, nacional, do espaço geográfico demarcado, para se vir a constituir como estado.

28 "No primeiro degrau está a comuna, mais acima o condado, enfim o Estado" (Tocqueville 1981: 122). 


\section{Bibliografia}

Astre, Georges-Albert e A.-P. Hoareau (1997), El universo del western, Caracas/Madrid, Editorial Fundamentos.

Benavente, Fran (2017), El héroe trágico en el western, Sevilla, Athenaica.

Carvalho, I. C. de Moura e C. A. Steil (2013), "Natureza e imaginação: o deus da ecologia no horizonte moral do ambientalismo", Ambiente \& Sociedade, On-line version ISSN 18094422; São Paulo, Ambient. soc., vol. 16, no.4 Oct./Dec. https://www.scielo.br/scielo. php?pid=S1414-753X2013000400007\&script=sci_abstract\&tlng=pt (último acesso em 15/10/2020).

Dort, Bernard (1966), "La Nostalgie de l'épopée", Le Western, Paris, UGE - 10/18.

Durand, Gilbert (1983), o Mito e a Sociedade, trad. Nuno Júdice, Lisboa, Regra do Jogo.

Emerson, Ralph Waldo (2011), Natureza, Brasil, Editora Dracaena, <https://elivros.info/autor/ Ralph-Waldo-Emerson> (último acesso em 15/10/2020).

Faulkner, William (1958), Requiem por Uma Freira, trad. Luís Francisco Rebelo, Lisboa, Minerva [1951].

Ivanov/Lotman /Ouspensky/Piatigorski/Toporov (1970), "Thèses pour l'étude de la sémiotique des cultures", in Recherches internationales à la lumière du marxisme, $\mathrm{n}^{0} 81$, Paris Nouvelle Critique, pp. 125-156.

Jorge, Carlos J. F. (2005), "O Horizonte Mítico do Western em Shane de Schaefer e Stevens", in Ariane/Catographies, $\mathrm{n}^{0}$ 18/19/20, Lisboa, FL/Universidade de Lisboa.

Lacan, Jacques (1981), "Les Psychoses" 1955-1956, Le Seminaire, livre III, Paris, Seuil.

Lévi-Strauss, Claude (2009), "Natureza e cultura", Revista Antropos - Volume 3, Ano 2, Dezembro de 2009: 17-26, Paris, Antropos, acessível em <http://revista.antropos.com. br/downloads/dez2009/Artigo\%203\%20-\%20Natureza\%20e\%20Cultura\%20-\%20 Claude\%20L\%E9vi-Strauss.pdf> (último acesso em 15/10/2020).

Lukács, Georg (1962), The Historical Novel, Merlin Press, London.

-- (1986), A teoria do romance, trad. Alfredo Margarido, Lisboa, Presença [1920].

Mayer, Hervé (2017), La construction de l'Ouest américain dans le cinema Hollywoodien, Atland, Neuilly-sur-Seine/F.

Melville, Herman (1990), The Confidence-Man, Penguin, London.

Mouravieff, Boris (1962), Gnôsis, étude et commentaires sur la tradition esotérique - l'ortodoxie orientale, La Colombe, Paris.

Niemeyer, Mark (2018), Herman Melville - The Confidence-Man, F- 9220/ Neuilly-sur-Seine/F, Atlande.

O'Donell, Patrick, (2010), "Nomadism and Authority in As I Lay Dying", in As I Lay Dying, London, W.W. Norton \& Company, 329-335.

Schaefer, Jack (1975), Shane, New York, Bantam [1949].

Simpson, Paul (2006), The Rough Guide to Western, London, Rough Guides/Penguin.

Tocqueville, Alexis de (1981), La démocratie en Amérique, GF- Flammarion, Paris (tradução de 
Cadernos de Literatura Comparada

Notas sobre o outro lado das fronteiras míticas do western

Eduardo Brandão, São Paulo, Martins Fontes, 2005).

<https://edisciplinas.usp.br/pluginfile.php/2804534/mod_resource/content/o/ tocqueville_a-democracia-na-america-vol-1.pdf pp. 436-437> (último acesso em 15/10/2020). 